\title{
Evaluation of Job Insecurity in Individuals with Chronic Low Back Pain
}

\author{
Bora Tetik ${ }^{1}$, Ramazan Paşahan ${ }^{1}$ \\ ${ }^{1}$ Department of Neurosurgery, Faculty of Medicine, Inonu University, Malatya, Turkey \\ Received: 20 June 2020, Accepted: 21 August 2020, Published online: 31 August 2020 \\ (C) Ordu University Institute of Health Sciences, Turkey, 2020
}

\begin{abstract}
Objective: It is natural for individuals who have chronic low back pain to perceive job insecurity because of the difficulty of finding a new job in either public or private sectors. In this study, we investigated the fear of losing job in individuals who admitted to our hospital with chronic low back pain by applying Job Insecurity Scale.

Method: Sociodemographic data form and Job insecurity scale were applied to patients working in the private sector, who admitted to our hospital with chronic low back pain. IBM SPSS Statistics 25.0 software was used in analysis. A value of $\mathrm{p}<0.05$ accepted to be statistically significant.

Results: A total of 118 people, 41 (34.7\%) female and 77 (65.3\%) male, participated in the study. Among patients with chronic low back pain, those who underwent surgery for low back pain, those with pain lasting more than 1 year, and those over the age of 50 years were found to have higher scores on the job loss anxiety scale.

Conclusion: Recent studies has shown that low back pain is the 2nd most frequent pain. We think that patients with chronic low back pain should be given psychological support because of the anxiety of losing job.
\end{abstract}

Key words: Chronic low back pain, job insecurity, Job loss anxiety

Suggested Citation: Tetik B, Pasahan R. Evaluation of Job Insecurity in Individuals with Chronic Low Back Pain. Middle Black Sea Journal of Health Science, 2020; 6(2):172-176.

\section{Address for correspondence/reprints:}

Bora Tetik

Telephone number: +90422431066011773

ORCID-ID 0000-0001-7696-7785

E-mail: drboratetik@hotmail.com

DOI : 10.19127/mbsjohs.755691

\section{Introduction}

Pain is one of the most common symptoms affecting individual's bio-psycho-socially and impairing the quality of life. However, chronic pain challenges both individuals and physicians because it is difficult to treat. Low back pain that persists for more than 6 months is considered to be chronic and is generally due to mechanical low back pain (Braun et al, 2014; Will et al, 2018). In the literature, it has been noted that chronic low back pain is one of the most frequently observed musculoskeletal disorders (Oksuz, 2006). The posture of individuals with chronic low back pain is impaired in walking and sitting. This causes additional problems, such as numbness and tingling in the legs due to nerve 
compression, and the development of atrophy due to muscles not working. Low back pain can have many causes, most of which are nonspecific. Specific causes include disc hernias, tumors, osteoporosis and rheumatoid arthritis (Koes, 2006).

It is natural for individuals who experience chronic back pain to feel job insecurity due to the difficulty of finding a new job in both the public and private sectors. In this study, we tried to investigate the fear of job loss due to chronic low back pain in individuals who were admitted to outpatient clinics of our hospital, by using a sociodemographic data form and the Job Insecurity Scale.

\section{Methods}

In this study, patients who were admitted to the Neurosurgery, Physical Therapy, and Family Medicine outpatient clinics of Inonu University Faculty of Medicine in June 2020, who were working in the private sector, and who volunteered to participate were included. Informed consent of the patients was obtained verbally. The sociodemographic data form and the Job Insecurity Scale were applied to the participants. Data were summarized by number (percent), mean \pm standard deviation, and median (min-max) according to different variables. The suitability of numerical variables to normal distribution was examined by using Shapiro-Wilk test. In independent samples, the presence of a statistically significant difference between the sub-categories in terms of quantitative variables was examined using t-test and KruskalWallis test. After the Kruskal-Wallis test, multiple comparison tests were examined using the Bonferroni-corrected Mann-Whitney U test. A value of $p<0.05$ was accepted as statistically significant. IBM SPSS Statistics 25.0 software was used in the analysis. Ethics committee approval was received for this study from Nonclinical Research Ethics Committee of Inonu University.

The Job Insecurity Scale was developed by Ashford, Lee, and Bobko in 1989. The validity and reliability of the scale in Turkish was performed by Aslan et al in 2011. This scale consists of two parts and includes 13 questions. It is a five-answer Likerttype scale ranging between absolutely impossible and absolutely possible. The first part consists of 10 questions that measure perceived job insecurity and threat of losing job, and the second part consists of three questions that measure the level of job insecurity. In the first part, each answer is scored between 0 and 4 and the score increases as job insecurity increases. The second part is scored inversely, i.e., the answer "absolutely not possible" is scored 4 points, whereas "absolutely possible" is scored 0 points. In the reliability study of the scale, the $\alpha$ value was found to be $0.74-0.83$. In the Turkish validity study conducted by Aslan, $\alpha$ was found to be 0.88 , while reliability for 13 th question was found to be $\alpha=0.78$. To the best of our knowledge, there was no study using this scale.

\section{Results}

A total of 118 people, 41 (34.7\%) female and 77 (65.3\%) male, participated in the study. The average age was $35.42 \pm 8.93$ years. Fifty-seven $(48.3 \%)$ of the participants were office workers. Considering the duration of working in the profession, $36(30.5 \%)$ participants had been working in the same job for more than 5 years. Considering the duration of low back pain, $55(46.6 \%)$ of the participants had low back pain for more than one year. Sociodemographic data of the participants are given in table 1 .

In our study, the mean score of job insecurity was $24.48 \pm 4.92$. When compared according to gender, the mean score of the first part of the scale, which measured perceived threats of job insecurity and job loss, was $24.80 \pm 5.06$ in women and $24.31 \pm 4.88$ in men; this difference was not statistically significant $(\mathrm{p}=0.60)$. When compared according to profession, the scores of those working in a job that required heavy lifting was higher $(25.40 \pm 6.07)$; however, this difference was not statistically significant $(p=0.19)$. When compared according to duration in the profession, the mean job insecurity score of those who had been working longer than 15 years was higher $(25.33 \pm 4.68)$, but again, there was no statistically significant difference. The mean score of those who had undergone surgery was statistically significantly higher than those who had no surgery ( $p$ $=0.03$ ). When the scores of the Job Insecurity Scale were compared according to age group, the mean score of those who were older than 50 years of age was statistically significantly higher than those between the ages of 20 and 30 years $(p=0.04)$. The comparison of the mean scores of Job Insecurity Scale according to sociodemographic data of the participants is given in table 2 . 


\section{Evaluation of Job Insecurity in Individuals}

Table 1: Sociodemographic data of the cases

\begin{tabular}{|c|c|c|}
\hline & $\mathbf{n}$ & $\%$ \\
\hline \multicolumn{3}{|l|}{ Gender } \\
\hline Female & 41 & 34.7 \\
\hline Male & 77 & 65.3 \\
\hline Total & 118 & 100.0 \\
\hline \multicolumn{3}{|l|}{ Type of profession } \\
\hline Office work & 57 & 48.3 \\
\hline Requiring physical activity & 41 & 34.7 \\
\hline Predominantly heavy lifting & 20 & 16.9 \\
\hline Total & 118 & 100.0 \\
\hline \multicolumn{3}{|l|}{ Years in the profession } \\
\hline $0-\quad 5$ years & 33 & 28.0 \\
\hline $5-10$ years & 36 & 30.5 \\
\hline $10-15$ years & 28 & 23.7 \\
\hline 15 years & 21 & 17.8 \\
\hline Total & 118 & 100.0 \\
\hline \multicolumn{3}{|l|}{ Duration of low back pain } \\
\hline 6 months & 21 & 17.8 \\
\hline 6-12 months & 42 & 35.6 \\
\hline$>12$ months & 55 & 46.6 \\
\hline Total & 118 & 100.0 \\
\hline \multicolumn{3}{|l|}{ Frequency of low back pain } \\
\hline Only once & 18 & 15.3 \\
\hline Once in a month & 36 & 30.5 \\
\hline Once in a week & 35 & 29.7 \\
\hline 2-3 times a week & 25 & 21.2 \\
\hline More than 4 times a week & 4 & 3.4 \\
\hline Total & 118 & 100.0 \\
\hline \multicolumn{3}{|l|}{ History of trauma } \\
\hline Yes & 37 & 31.4 \\
\hline No & 81 & 68.6 \\
\hline Total & 118 & 100.0 \\
\hline \multicolumn{3}{|l|}{ History of surgery } \\
\hline Yes & 37 & 31.4 \\
\hline No & 81 & 68.6 \\
\hline Total & 118 & 100.0 \\
\hline \multicolumn{3}{|l|}{ Duration of watching TV } \\
\hline$<3$ hours & 69 & 58.8 \\
\hline$>3$ hours & 49 & 41.5 \\
\hline Total & 118 & 100.0 \\
\hline
\end{tabular}

\section{Discussion}

In developing countries like ours, anxiety about losing a job may lead to psychological consequences, because being employed allows the individual to be financially beneficial and feel productive and socialized. Fear of losing a job causes anxiety and leads to diminished working performance in individuals. Chronic low back pain is a particularly important disease that may cause job loss, disability and anxiety (Mammadow, 2018).

In studies of chronic low back pain, the number of women with the condition is reported to be higher than the number of men, and this has been attributed to the fact that chronic low back pain may be a psychosocial pathological condition (Brinkhaus et al, 2006; Namgwa et al, 2016).
Table 2: The comparison of the mean scores of job insecurity scale according to sociodemographic data of the participants

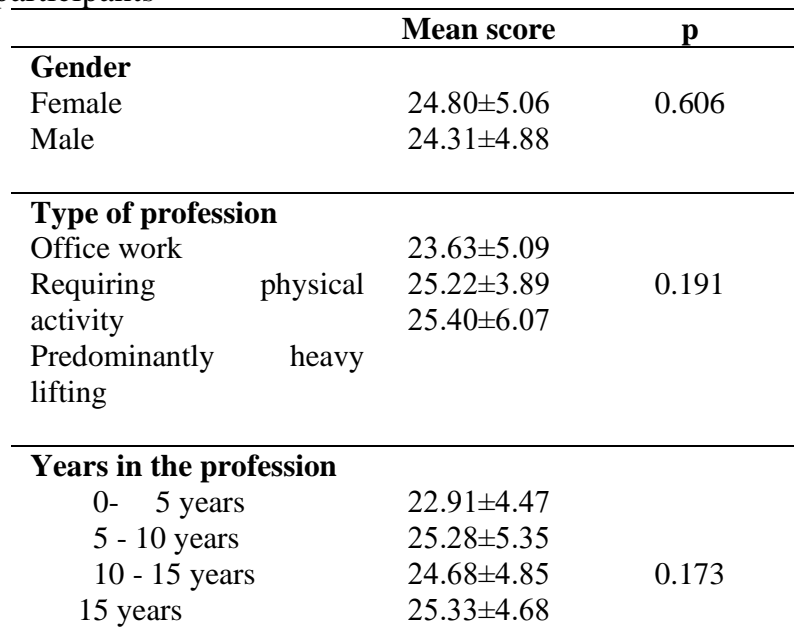

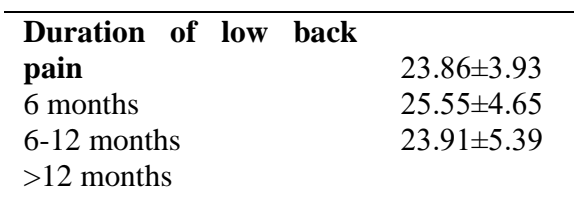

\begin{tabular}{lc}
\hline $\begin{array}{l}\text { Frequency of low back } \\
\text { pain }\end{array}$ & $22.5(16-$ \\
Only once & $30)$ \\
Once in a month & $24(15-34)$ \\
Once in a week & $25(14-34)$ \\
2-3 times a week & $23(16-37)$ \\
More than 4 times a week & $28(24-35)$
\end{tabular}

\begin{tabular}{lll}
\hline History of trauma & & \\
Yes & $24.70 \pm 5.90$ & 0.77 \\
No & $24.38 \pm 4.45$ & \\
& & \\
\hline History of surgery & & \\
Yes & $26.43 \pm 4.55$ & \\
No & $23.59 \pm 4.85$ & $\mathbf{0 . 0 0 3}$
\end{tabular}

\begin{tabular}{lll}
\hline $\begin{array}{l}\text { Duration of watching TV } \\
<3 \text { hours }\end{array}$ & & \\
$>3$ hours & $25.13 \pm 5.23$ & \\
& $23.57 \pm 4.34$ & 0.08 \\
\hline
\end{tabular}

However, in some studies, the number of men with chronic low back pain was more than twice the number of women (Aslan, 2011; Mammadow, 2018). In our study, the number of men was almost two times higher than the number of women. This may be due to the fact that the number of working women is less than the number of working men, since our society is still patriarchal, and men engaged more frequently in work that requires heavy lifting. In the study by Aslan, the mean score of perceived job threat subdimension of the Job Insecurity Scale was $6.94 \pm 5.34$ (Aslan, 2011). In our study, it was $24.80 \pm 5.06$ in women and $24.31 \pm 4.88$ in men. The difference between our and Aslan's study may be because we 
conducted this study on individuals with chronic low back pain and working in the private sector whereas Aslan's study was conducted on individuals working in information sector.

In Aslan's study, in which the Turkish validity of the Job Insecurity Scale was performed, the level of job insecurity was found to be higher in men than women (Aslan, 2011). In our study, women's anxiety scores were higher than men's. We suggest that this difference may be due to the fact that women are generally more anxious than men, and it is more difficult for women to find a job than men.

In our study, job insecurity anxiety was found to be statistically higher in those who had been suffering with low back pain for more than 1 year than those who had been suffering less than 1 year. This may be due to the fact that the patients who have chronic pain with limited treatment options may experience loss of productivity; therefore they have fear of losing their jobs (Ozkan, 1990).

In our study, we found that Job Insecurity Scale scores of patients who had undergone surgery due to low back pain were significantly higher than those who did not have surgery. This may be because patients who are suffering low back pain despite surgery may fear that they would remain untreated and that they would be unable to work, in time. We also found that the Job Insecurity Scale scores of the patients who were over 50 years of age were statistically significantly higher than those who were between 20 and 30 years of age. This may be because they think that finding a new job at advanced ages would not be easy. This condition may cause them to delay required therapy and consequently may worsen their condition. Therefore, we suggest that psychological support may be worthwhile for patients with low back pain.

In the study by Milliken et al, it was suggested that uncertainty about current job makes it difficult for individuals to make decisions about their future regarding their business and private life (Milliken, 1987). In our study, the Job Insecurity Scale scores of those who worked for more than 15 years, who had low back pain for 6-12 months, who had more than four low back pain a week, and who had trauma in the low back were found to be higher, however the differences were not statistically significant. This may be because those who have been working for a longer time may perceive the risk of losing job more strongly, and those who have trauma and have pain for between 6 months and 1 year may fear undergoing surgery or long-lasting treatments which can preclude them from working. In general, the uncertainty that occurs due to the lack of complete treatment may cause individuals to lose control and increase the feeling of helplessness (Wichert, 2001; Gokcek et al, 2018).

The fact that there are no other studies investigating the Job Insecurity Scale in the literature, except ours and the Aslan study increases the value of our study. However, a limitation of our study is that it was conducted only in a 3rd step hospital; therefore, it cannot be generalized to the general population.

\section{Conclusion}

In our study, the patients who underwent surgery for low back pain, those who have been suffering for more than 1 year, and those over 50 years old were found to have higher scores on the Job Insecurity Scale. In recent studies, it was reported that low back pain is the 2nd most common pain. Individuals with chronic low back pain may avoid surgery or may not participate in the suggested therapies due to the fear of being incapacitated and losing their jobs. We suggest that patients with chronic low back pain, in addition to receiving conventional therapies, should be given psychological support because of the anxiety of losing their job.

Ethics Committee Approval: The study was approved by ethics committee of Inonu University (Decision No: 2020/805). The study was performed following the aid of the ethical standards down in the 1964. Declaration of Helsinki and its later amendments.

Peer-review: Externally peer-reviewed.

Author Contributions: Consept- B.T.; DesingB.T.; Materials: B.T.; Data Colletion and/or Processing- B.T, R.P.; Literature Rewiev-B.T, R.P.; Writing- B.T, R.P.; Critical Rewiev- B.T.

Conflict of Interest: No conflict of interest was declared by the authors.

Financial Disclosure: The authors declared that this study hasn't received no financial support.

\section{References}

Aslan K. Investigation of the Effects of Job Insecurity and Job Losing Anxiety on Work Efficiency and Work Productivity: A Research in the Informatics Sector. Master's thesis, 2011.

Braun J, Baraliakos X, Regel A, Kiltz U. Assessment of spinal pain. Best Practice\&Research Clinical Rheumatology 2014;28: 875-887. 


\section{Evaluation of Job Insecurity in Individuals}

Brinkhaus B, Witt CM, Jena S, Linde K, Streng A, Wagenpfeil S, Irnich D, Walther HU, Melchart D, Willich SN. Acupuncture in patients with chronic low back pain: a randomized controlled trial. Arch Intern Med. 2006:27:166(4):450-457.

Gokcek E, Kaydu A. The Effect of the Lomber Disc Hernia on Anxiety / Depression in Adults Van Tip Derg 2018;25(3): 312-316.

Koes BW, van Tulder MW, Thomas S. Diagnosis and treatment of low back pain. BMJ 2006;332:1430 1434.

Mammadow E. The Relationship Between Pain, Quality of Life, Depression, Anxiety And Sleep In Patients With Chronic Low Back Pain Thesis 2018.

Milliken FJ. "Three types of perceived uncertanity about the environment: stage, effect, and response uncertanity", Academy of Management Review, 1987;12(1):133-143.

Namgwa KJ, Terkura A, William Y, Daniel MD, Cornilius EI. Depression in patients with chronic low back pain: A hospital-based study. Niger J Surg Res 2016;17:1-4.

Oksuz E. Prevalence, Risk Factors, and PreferenceBased Health States of Low Back Pain in a Turkish Population. Spine 2006;31(25):968-972.

Ozkan S. Psychiatric Medicine: Consultation-liasion psychiatry. Klinik Psikofarmakoloji Bulteni; 1990;1(1):10-17

Wichert I. "Job in security and work intensification, The effects of an health and well-being", Burchell, Brendan (Editor), Job Insecurity\&Work Intensification. 2001.

Will JS, Bury DC, Miller JA. Mechanical Low Back Pain. Am Fam Physician 2018 Oct 1;98(7):421428. 